\title{
Interações entre o Sistema da Medicina e da Saúde: observações a partir da Teoria dos Sistemas Sociais
}

\author{
Interactions Between the Medicine and Health System: observations from \\ Social System Theory
}

\author{
Leonel Severo Rocha ${ }^{1,2}$ \\ Gabrielle Jacobi Kòlling ${ }^{3,4}$ \\ Gustavo Andre Olsson ${ }^{5}$ \\ ${ }^{1} 1$ Universidade do Vale do Rio dos Sinos, Porto Alegre, RS, Brasil \\ ${ }^{2}$ Universidade Regional Integrada do Alto Uruguai, Erechim, RS, Brasil \\ ${ }^{3}$ Universidade Municipal de São Caetano do Sul, São Paulo, SP, Brasil \\ ${ }^{4}$ Universidade São Francisco, São Paulo, SP, Brasil \\ ${ }^{5}$ Universidade do Vale do Rio dos Sinos, São Leopoldo, RS, Brasil
}

\begin{abstract}
Resumo: Os limites e a relação do sistema médico com o da saúde são pautas para discussão na teoria dos sistemas, considerando que Luhmann abordou somente o sistema médico. A função do sistema médico está vinculada à cura e ao tratamento de doenças. Já o sistema da saúde apresenta-se ainda em processo de construção. Assim, a partir da utilização do método sistêmico, o objetivo deste trabalho é analisar e compreender a operacionalidade do código do sistema médico, bem como observar, a partir da própria teoria, a relação da prevenção com o sistema médico e a relação deste com o sistema da saúde.
\end{abstract}

Palavras-chave: Sistema Médico. Sistema da Saúde. Prevenção. Código.
Abstract: The limits and the relation of the medical system to that of health are a subject for discussion in systems theory, considering that Luhmann addressed only the medical system. The function of the medical system is linked to healing, to the treatment of diseases. The health system is still under construction. Thus, the objective is to analyze and understand the operability of the code of the medical system, as well as to observe, from the theory itself, the relation of prevention with the medical system and its relationship with the health system. The method of analysis will be systemic.

Keywords: Medical System. Health System. Prevention. Code.

Recebido em: 10/11/2018

Revisado em: 25/08/2019

Aprovado em: 29/09/2019 


\section{Introdução}

A relação do sistema médico com o sistema da saúde ainda se mostra desafiadora para os estudiosos da teoria dos sistemas sociais, tendo em vista que Luhmann nunca tratou propriamente do sistema da saúde; apenas, de um modo genérico, discutiu o sistema médico.

O foco do sistema médico está na atuação dos médicos, com a pretensão de selecionar a intervenção apropriada sobre o corpo doente, por meio de diagnósticos e tratamentos, com o propósito de alcançar um estado de saúde. A função desse sistema está vinculada à vida humana e à saúde para o tratamento de doenças, ou seja, o sistema opera unicamente quando verificada a hipótese de doença, o código negativo do sistema médico. Nesse aspecto, o ambivalente funcional da doença, qual seja, a saúde, não é, em um primeiro momento, o aspecto determinante para o funcionamento do sistema. Por consequência, em tese, não se vislumbra espaço para a integração de ações preventivas no âmbito desse sistema.

O sistema da saúde, por sua vez, é uma construção teórica ainda em desenvolvimento. Ela não foi abordada por Luhmann, mas por Corsi, Martini e Schwartz. Este último concebe a ideia de que o sistema da saúde é um pressuposto, é um sistema que se acopla ao sistema da medicina (SCHWARTZ, 2003). Já Martini, com Corsi, observa que, em que pese Luhmann não tenha se debruçado sobre o sistema da saúde, a própria teoria sistêmica, com suas bases interdisciplinares, fornece subsídios suficientes para observar a saúde como um sistema diferenciado funcionalmente (MARTINI, 2015).

Nesse sentido, a reflexão acerca dos sistemas médico e da saúde com a prevenção implica em dificuldades que norteiam o objetivo do trabalho, ou seja, analisar e compreender a operacionalidade do sistema médico e de seu respectivo código, bem como discutir o papel da prevenção e a sua relação com os sistemas da saúde e da medicina. A delimitação exige a abordagem do sistema da saúde, uma vez que as ações preventivas não são concretizadas unicamente pelo sistema médico e ultrapassam a atuação restrita dos médicos. Assim, procura-se observar a delimitação do código do sistema médico, visando a compreender o papel que a pre- 
venção de doenças, potencialmente, concretizaria em tal sistema, assim como sua relação com o sistema da saúde, de forma a verificar a possibilidade de imbricação entre os sistemas.

Cumpre destarcar que, no que tange ao escopo do períodico, a temática ora apresentada está em consonância com a linha editorial, visto que o artigo aborda tema inerente à teoria do direito e à relação direito, Estado e sociedade. Os sistemas que integrarão a discussão teórica estão amplamente inseridos na interface direito e sociedade. Na análise do sistema do direito, da medicina e da saúde, tem-se, também, uma discussão de teoria do direito, especialmente no tocante aos limites e às possibilidades das expectativas jurídicas relacionadas à saúde. E é apenas a partir de uma construção teórica sólida que passa a ser possível buscar uma concretização dogmática no direito, especialmente no direito brasileiro, quando, ao mesmo tempo em que o sistema jurídico sinaliza pela existência de um direito fundamental à saúde, a doutrina jurídica aponta lapsos de efetividade. Essa é a direção buscada, ou seja, o estabelecimento de elementos teóricos com o intuito de gerar ressonâncias na dogmática jurídica no sentido de provocar o desenvolvimento de subsídios para a exigibilidade do direito à saúde e de sua efetividade.

No que tange à metodologia de abordagem, será utilizado o método sistêmico, ou seja, parte-se da observação de segunda ordem, bem como das categorias sistêmicas de sistema, ambiente, código, função, entre outras, para, então, observar, descrever e analisar o tema.

A estrutura do trabalho será dividida em cinco partes. A primeira consiste na introdução do tema; a segunda fará uma contextualização dos sistemas médico e da saúde na teoria dos sistemas sociais. A terceira reconstruirá o código do sistema da medicina, discutindo paralelamente o sistema da saúde, objetivando estabelecer a relação do código com a noção de "saúde", demonstrando minimamente a fluidez histórico-temporal da semântica dessa categoria linguística; e, a quarta parte, a partir da construção jurídico-dogmática brasileira, procurará integrar a atuação preventiva no âmbito do sistema médico e do sistema da saúde (buscando estabelecer uma ligação teórica entre ambos), a partir da compreensão de que, havendo fluidez no que concerne à fronteira do ambivalente funcio- 
nal saúde/doença, necessariamente, há espaço teórico para a atuação preventiva. À guisa de conclusão, serão apresentadas algumas observações finais.

\section{Contextualização dos Sistemas Médico e da Saúde na Teoria dos Sistemas Sociais}

Em seus estudos, Luhmann nunca tratou propriamente de um "sistema da saúde" (MARTINI, 2015); porém, observou o sistema médico de um modo preliminar. No contexto dessa observação, pode-se destacar que o objetivo orientador da atuação dos médicos está inserto na intervenção apropriada, com consequências desejadas, sobre o corpo doente. Para tanto, valem-se do emprego de diagnósticos e de tratamentos sobre os quais há determinada certeza, conhecimento teórico, tencionando alcançar o estado de saúde - uma relação envolvendo os papéis médico/paciente (LUHMANN, 2007). Daí, inclusive, o caráter de ciência aplicada da medicina (LUHMANN, 1990).

Inicialmente, a medicina poderia se diferenciar de outros sistemas a partir de uma separação lógica que a constitui: noção de interno/externo. Aquilo que pode ser pensado como "interno" corresponderia aos elementos e às estruturas constitutivas, separando-o daquilo que não é (aspecto externo). Há uma separação, como o exemplo de Maturana e Varela (1997, p. 14-15) demonstra:

[...] percebi de que era essa circularidade e dinâmica produtiva molecular constitutiva do vivo. Isto é, [...] o que definia e de fato constituía os seres como entes autônomos que resultavam autorreferidos em seu simples operar era o fato de que se tratavam de unidades separadas que existiam como tais na contínua realização e conservação da circularidade produtiva de todos os seus componentes, de maneira tal que tudo que acontecia com eles acontecia na realização e na conservação dessa dinâmica produtiva, que os definia e ao mesmo tempo os constituía em sua autonomia. 
Separação que, por outro lado, implica numa íntima relação entre organização e estrutura (ROCHA, 2017). A partir dessa separação, é possível verificar as consequências relevantes para a observação de seu funcionamento. Os problemas éticos da medicina, por exemplo, não são resolvidos internamente a esse sistema, ocupado em tratar o doente, ou mesmo com base na ética como disciplina, mas por determinações "do externo", tomadas por comissões deliberativas que prescrevem comportamentos de forma isolada, normalmente, com base em critérios jurídicos ou econômicos (LUHMANN, 1990).

$\mathrm{Na}$ verdade, a própria distinção entre interno e externo foge ao escopo de "tratar o corpo doente". Se os problemas éticos não têm utilidade para o tratamento de doentes, poderia se falar que, na medicina, há um subsistema para o tratamento de doenças ou, alternativamente, seria possível falar do tratamento de doenças como um sistema autônomo, de ciência aplicada, de função que não poderia ser absorvida por outro sistema (SCHWARTZ, 2003).

O método para isolar a autonomia de um sistema de função consiste na identificação de um critério para isolar a contingência de valores desse sistema: a codificação binária ${ }^{1}$. A codificação binária é a transcrição dos valores de um sistema de função para esquematismos binários de "ser/ não-ser", "verdadeiro/falso", "incluído/excluído", os quais constituem uma diferença, estabelecendo uma oposição ou-isto-ou-aquilo². Quando um "valor" do sistema de função pode ser, alternativamente, intercambia-

\footnotetext{
${ }^{1}$ Por exemplo: "Los códigos se desempeñan - como otras distinciones también - como forma de dos lados que un observador puede o no utilizar. Tienen también la singularidad de una distinción en la medida en que cada vez sólo se indica un lado y no el otro simultáneamente; solo así se prestan a ser punto de enlace y la mismidad de lo diferente - con lo cual se demostraría a sí mismo que es imposible.” (LUHMANN, 2007, p. 281). ${ }^{2}$ No original: "Los medios de comunicación simbólicamente generalizados requieren un código unitario (código central) para todo el ámbito de su médium. Un código consiste de dos valores opuestos y en este plano (aunque obviamente no en 'la vida') excluye terceros y más valores. Con ello, la posibilidad indeterminada (tendencialmente en aumento) de rechazar una propuesta de sentido comunicada se convierte en un duro o-esto-o-lo-otro; es decir, una situación 'análoga' se transforma en 'digital', y con ello se gana una pregunta de decisión clara que resulta ser la misma para alter y para ego.” (LUHMANN, 2007, p. 280-281).
} 
do para "não-valor", pode ser examinada sua contingência/dispensabilidade para a reprodução operativa do sistema (não-ser) e sua capacidade de criar conexões, isto é, de condicionar e ser condicionado pelos programas internos ao sistema (ser) (LUHMANN, 1990; ROCHA, 2010).

Se o sistema do tratamento de doenças puder se transcrito dessa maneira binária, em que a tradução de seus valores prescinda dos valores dos códigos de outros sistemas, mantendo sua assimetria interna, então estará caracterizado o tratamento de doenças como sistema de função autônomo. Normalmente, sistemas de função trabalham com codificações binárias, alocando seu objetivo como valor positivo estruturante das operações do sistema. No caso do tratamento de doenças, não é a saúde que gera reflexos operacionais, mas a doença (o valor negativo) (LUHMANN, 1990). Isto é, no tratamento de doenças, a saúde é um valor negativo do sistema; é qualificado como a negação do estado de doença, que foi ou virá ${ }^{\text {. De }}$ fato, nessa lógica, não haveria sentido no fato de o médico observar a saúde, porque esse seria um estado do corpo no qual não há necessidade de intervenção; ao contrário, se a atuação se apresenta no sentido de busca da cura ou do estado de saúde (o estabelecimento da integridade do vivo ou, melhor, a manutenção do estado autopoiético do vivo ${ }^{4}$ ).

Alerta Luhmann, no entanto, que os conceitos de "são" e de "doente" não indicam um particular estado físico ou psíquico, mas têm valor de código, no qual o valor positivo é o da doença, e o negativo é o da saúde: o que vai importar para este sistema não é a saúde, mas sim a doença, já que só esta importa para os médicos (MARTINI, 2015).

Essa estrutura do sistema de função de tratamento de doenças explica a dificuldade em se formularem teorias para o sistema a partir de sua finalidade, especialmente porque a saúde não contribui para a teoria do tratamento de doenças - em oposição a outros sistemas de função em que

\footnotetext{
${ }^{3}$ Nesse mesmo sentido, ver: Corsi, Baraldi e Esposito (1996, p. 143).

${ }^{4}$ Nesse sentido, de forma complementar: "Uma máquina autopoiética é uma máquina organizada como um sistema de processos de produção de componentes concatenados de tal maneira que produzem componente que: i) geram processos (relações) de produção que os produzem através de suas contínuas interelações e transformações, e ii) constituem à máquina como uma unidade no espaço físico." (ROMESÍN, 1997, p. 72).
} 
o valor positivo na posição de finalidade do sistema de função é gerador de conexões e reflexões internas ao sistema (LUHMANN, 2007).

Se "[...] em todos os setores, transformações [...] são produzidas claramente nas recodificações e na teoria da reflexão que as acompanham [...]" (LUHMANN, 2007, p. 139), é consequência que, no tratamento de doenças, sistema de função em que a ação visa ao valor da reflexão saúde - e em que a saúde se coloca como valor negativo do sistema -, as estruturas e transformações surgem nos locais em que haja maior volume de doenças ou doentes.

Evidencia-se, também, a interseção entre medicina e economia, que, no sistema de função de tratamento das doenças, o problema é a falta de doentes ou doenças, que limita o desenvolvimento desse sistema, inclusive por interesses políticos (LUHMANN, 1990).

Outro motivo pelo qual se poderia dizer que o sistema de tratamento de doenças prescinde das reflexões advindas da sua finalidade, saúde, é por meio da observação consciente do corpo. A percepção do corpo se dá de forma presente e contemporânea. No caso de lesões e doenças que manifestem dor, essa percepção é particularmente aguda (LUHMANN, 1990).

Médicos, pela medicina, trabalham com a contenção da dor e com a gestão do tempo para medicar e curar. As intervenções e, inclusive, a comunicação, relacionadas ao paciente, se dão de forma contemporânea, e não em outra faixa de tempo. Nesse sentido, evidencia-se o caráter do tratamento de doenças de lidar com a doença e não de produzir saúde como objeto imediato (LUHMANN, 1990). Nos locais nos quais os médicos observariam/compreenderiam haver maior necessidade de atuação, haveria, tendencialmente, maior gama de atuação.

O problema está no fato de que as noções de doença/saúde, assim a de "necessidade", correspondem também a seleções realizadas pelo próprio sistema. Note-se que "[...] toda observación (incluyendo el conocer e al actuar) depende de la selección de una distinción, y selección significa dejar necesariamente algo de lado" (LUHMANN, 2007, p. 142). 
Em outras palavras, a preocupação da medicina com a vida humana e da saúde para o tratamento de doenças ressalta o fato de que a ação do sistema se dá somente quando alguém adoece. As doenças ocasionadas ou facilitadas pela forma como está estruturada a sociedade são de particular importância, gerando consequências para o saber, para a prática comunicativa, para as organizações e para as finanças (LUHMANN, 1990).

O sistema da medicina tem a função de tratar doenças, e, nisso, visualiza-se o papel de prevenção e compensação de danos (pretende manter ou recuperar a saúde). O mau funcionamento dessa prevenção/compensação é o aspecto problemático: isto é, a possibilidade de saúde não alcançada (LUHMANN, 1990). Nessa lógica, o sistema de função de tratamento de doenças, cabe observar, não é particularmente adequado para lidar com métodos preventivos pela prescrição de condutas sociais, para grupos de risco potencial, por exemplo, quer porque as doenças são permeadas de particularidades na sua manifestação em corpos individuais, quer porque a realidade é mais complexa (contingente) que a linearidade do raciocínio causa-consequência ${ }^{5}$ abarcado pela ação preventiva ${ }^{6}$. Essa relação de causalidade é construída pelo observador o qual, por sua vez, constrói/modifica a realidade com a própria observação ${ }^{7}$.

Abstratamente, a atividade de prevenção comunica-se com a noção de "maneira correta", acarretando a orientação das operações do sistema; todavia, acaba deturpada em uma preocupação superficial sobre a abrangência técnica de condutas. Acontece de maneira semelhante com as categorias de enfermidades curáveis e não curáveis - em relação ao

5 "Cualquier intento de especificar las causalidades lleva a problemas cada vez mayores. Lo que acontecerá, jamás dependerá de un solo acontecimiento. Siempre hay un enlace de circunstancias de manera que la incertidumbre se multiplica a la par que la nitidez con la que se haya intentado el análisis. En el horizonte del pasado por lo menos se sabe lo que aconteció, aunque las condiciones causales permanezcan inexplicables. En el horizonte del futuro falta exactamente esta seguridad que desde la perspectiva de la vida hace prescindible un análisis causal. Y precisamente por eso el modo de observación que toma en consideración las causalidades es el que aumenta la discrepancia entre pasado y futuro [...]." (LUHMANN, 2006, p. 87).

${ }^{6}$ Até porque essa relação é construída por um observador.

${ }^{7}$ Nesse sentido, ver também: Ramdom (2002, p. 27-28). Sobre o impacto dessa percepção na construção dos paradigmas científicos, ver: Vasconcellos (2013). 
diagnóstico e ao tratamento -, em que a codificação secundária remete a discussão a outros sistemas de função da sociedade, com reações no campo social (LUHMANN, 1990). Por exemplo, a possibilidade de cura ou não de alguma enfermidade não depende exclusivamente da atuação médica; depende, também, e em algumas hipóteses de forma necessária, da capacidade de outros sistemas, como o da ciência. Note-se que a doença é construída também a partir da observação de outros subsistemas, como o da biologia, que descobre e classifica eventuais agentes patogênicos (e a história do descobrimento das doenças nos serem humanos é bem elucidativa a esse respeito). Como aponta Herlich (2004, p. 384), “A história da saúde é também a história dos países e cidades, do trabalho, das guerras e das viagens". Hoje, inclusive, pode-se pensar em diversas "novas" doenças, a cada dia "descobertas" ou "construídas" socialmente: no senso comum, por exemplo, a ansiedade fora o mal do século XX e a depressão seria o do século $\mathrm{XXI}^{8}$. Já o tratamento, por sua vez, pode depender de desenvolvimentos teórico-científicos da biologia, da química, da farmacologia e assim por diante.

Dessa forma, a capacidade ou não de cura para a moléstia não depende exclusivamente do médico, mas da capacidade técnico-científica do ser humano em diagnosticar e de estabelecer meios de erradicar a doença, pressupondo, por óbvio, seleções anteriores (como a priorização desse tópico na comunicação social e etc.). A construção da doença e de sua cura concretizada no âmbito do sistema médico. A sociedade é que estabelece sentido (ROCHA, 2017).

Essas interdependências, na verdade, não privam o sistema de função do tratamento de doenças de sua autonomia; pelo contrário, aclaram que esse sistema age pelo próprio código e que diagnóstico e tratamento, informação e assessoria existem como matéria da medicina (LUHMANN, 1990). Afinal, são elementos que - traduzidos para o sistema - orientam seu funcionamento interno.

\footnotetext{
${ }^{8}$ Gerando atuação e preocupação da própria Organização Mundial da Saúde. Inclusive, no Dia Mundial da Saúde do ano de 2016, o tema fora o estresse no ambiente de trabalho. Ver: Organização Mundial da Saúde (2016), Estresse no ambiente de trabalho cobra preço alto de indivíduos, empregadores e sociedade.
} 
É oportuno destacar que Germano Schwartz e Sandra Martini trabalham com a ideia de sistema médico e da saúde a partir dos contributos teóricos de Luhmann. Schwartz partiu, em 2003, do sistema da saúde como pressuposto: um sistema autopoiético que apresenta acoplamento com a medicina. O autor utiliza o próprio Luhmann (SCHWARTZ, 2003) para corroborar a sua afirmação de que sistemas sanitários e médicos são sinônimos para o entendimento do fechamento operacional sanitário. A compreensão acerca do sistema sanitário autopoiético só pode ser operada mediante suas próprias limitações/orientações (SCHWARTZ, 2003). $\mathrm{O}$ autor aduz que o sistema sanitário ou médico é autônomo porque tem função própria, ou seja, ninguém pode se curar fora do sistema sanitário. Além disso, possui código próprio, que possibilita a clausura operativa e permite seu contato com o entorno.

Por sua vez, Sandra Martini $(2015$, p. 56) compreende que " $[. .]$. independentemente de Luhmann ter escrito de a saúde se constituir em sistema social [...] queremos mostrar que o ator deixa instrumentos suficientes para o entendimento da saúde como um sistema diferenciado funcionalmente". Em outras palavras, a partir das categorias teóricas básicas, é possível construir-se/distinguir-se o sistema que envolve a cura e a doença. Quando se reflete acerca do sistema da medicina, depara-se, quase que automaticamente, com o sistema da saúde. Isso acarreta um "desassossego", nas palavras de Martini.

O reflexo disso é que, há mais de dez anos, esse assunto tem sido discutido (saúde como um sistema social) por vários pensadores da teoria sistêmica, entre os quais a autora e, especialmente, Giancarlo Corsi. A questão de fundo desses autores, portanto, a qual perpassa este trabalho, é buscar compreender a operacionalidade do código desse sistema (da saúde), discutindo-o em relação ao da medicina, e, especialmente, discutir o papel da prevenção, elemento relevante no que se refere à saúde na sociedade contemporânea. 


\section{O Código, a Saúde e a Medicina}

É essencial a compreensão dos fundamentos do agir dos médicos, de como se orientam. E, como visto, isso está vinculado ao código binário do sistema e, exatamente por isso, com uma lógica recursiva, constitui-se em elemento imprescindível para a compreensão do sistema.

A diferenciação funcional dos sistemas está ligada a um esquema binário específico, por meio do qual há um processamento de informações recebidas. A binariedade exclui - ou pretende excluir - a corrupção dos sistemas, ou seja, uma espécie de individualidade, uma separação ou distinção lógica entre coisas. Ao fim, por meio da ideia de forma (dois lados), estabelecerá/formará uma unidade do sistema. Uma unidade traduzida pelo código binário (e eventuais códigos secundários) que, ao mesmo tempo, auxilia na compreensão da operatividade do sistema.

É o código saúde/doença, por exemplo, que traduz o funcionamento do sistema da medicina, e não o código dinheiro/não dinheiro. Isso significa uma operacionalidade com fundamento na existência da doença, independentemente da relação envolver capacidade de pagamento: o critério distintivo para a relação médico-paciente é a existência de uma situação de doença, independentemente de eventual aspecto econômico (e, apenas a título de observação, o juramento de Hipócrates, do âmbito médico, apontaria nesse sentido). A relação econômica pode perpassar a relação médica com maior ou menor relevância, inclusive no momento do diagnóstico (a partir de acoplamentos); porém, não se constitui em estrutura do sistema: não há como estabelecer a cura (mediante pagamento ou não) quando não há doença. Esse é, por exemplo, um dos elementos que leva - ou que deveria levar, sob o ponto de vista da dogmática jurídica - à tomada de decisões jurídicas considerando unicamente o código do direito, "ter-se o direito ou não", buscando-se afastar da discussão os aspectos relacionados com o custo econômico (o qual, paradoxalmente, está cada vez mais presente na jurisprudência e na atuação do Poder Público - os quais, por sua vez, acarretam ressonâncias comuncacionais na política e novas demandas por legislação - para mais ou menos consideração pelos custos, porém tudo em nome de "efetividade"). 
O mesmo problema pode ser pensado a partir da relação do sistema médico com o sistema da religião ou do direito. Sem a existência de uma tradução/criação de uma observação no âmbito do próprio sistema da saúde, não há o processamento neste sistema. Evidentemente, via acoplamentos, é possível que o sistema direito e o sistema da religião estabeleçam requisitos de atuação médica, influenciem na vedação de procedimentos, na compreensão da semântica daquilo que se entende por saúde ou doença. Todavia, o problema é racionalizado ("traduzido"), e a atuação se dá por intermédio do próprio sistema (ROCHA, 2017). Pode-se discutir juridicamente a possibilidade ou não de concretização de um aborto, e, até existir essa definição, há um bloqueio indireto do atuar médico (cuja operacionalidade da noção de saúde acaba irritada pela solução jurídica que, por sua vez, pode ter sido irritada por outros fatores). De outro lado, nas comunicações dogmáticas do direito, essa discussão é traduzida como existência do direito e sua efetividade.

Da mesma forma, as organizações do âmbito do sistema médico não integram em seus corpos de membros grupos de pessoas que não saibam operar adequadamente o código. Qualquer pessoa teria uma sensação de estranhamento se encontrasse atendendo no hospital curandeiros, benzedeiras ou outra pessoa a realizar tratamentos não focalizados naquilo que se entenda por "medicina" (considerando o paradigma médico).

Note-se como essa discussão é sensível na realidade brasileira, especialmente com a concretização do programa governamental "Mais Médicos": na verdade, a discussão envolve a aferição dos requisitos para reconhecer a situação de doença/saúde. Em outras palavras, a partir de um debate que ressalta a diferença entre os currículos dos cursos de medicina no Brasil e de Cuba, discute-se o pertencimento ou não ao grupo de pessoas que operam o sistema da medicina. É que, no fundo, o pertencimento/inclusão ao sistema da medicina se dá pelas carreiras ${ }^{9}$ e, no caso, pelo reconhecimento como médico. Se em um lado da relação há o paciente/ doente, no outro está o médico (ainda que exista uma gama de outros elementos a operacionalizar o sistema da medicina, como enfermeiros, técni-

\footnotetext{
${ }^{9}$ Sobre a questão da construção das carreiras profissionais como forma de inclusão no sistema social, ver: Moeller (2006. p. 91 e seguintes).
} 
cos, hospitais, etc.). Paradoxalmente, a partir de uma perspectiva da efetividade, ambas observam-se como forma de garantir um direito à saúde.

De qualquer forma, na estrutura binária, há um valor positivo (ou designativo), que traduz a capacidade de comunicação do sistema segundo sua função, e um valor negativo (valor sem designação), que representa a contingência da inserção do valor positivo no contexto sistêmico. O resultado da interação é a unidade (SCHWARTZ, 2003).

O código é uma espécie de "facilitador" das operações recursivas do sistema, bem como da função, e é o código que permite o reconhecimento da diferença entre o sistema e o entorno (ou, de outra maneira, entre os sistemas). $\mathrm{O}$ código possibilita a equivalência negativa para enfrentar a contingência do entorno (MANSILLA, 2001). No entanto, como visto, não se pode pensar no código do sistema médico exclusivamente na função do sistema - a saúde. É essencial que se pense na sua equivalente funcional - a doença (SCHWARTZ, 2003). De fato, exatamente pela noção de equivalência funcional, devem ser pensadas conjuntamente. A noção ou conceito de saúde passou por várias percepções, quais sejam: a saúde curativa, a saúde mágica, a saúde preventiva e a saúde promocional. Schwartz chama a atenção para o fato de todas as noções ou conceitos perpassarem o aspecto doença; esse é o elemento comum. A saúde tem seu equivalente funcional na doença e, se não fosse assim, não teríamos no sistema sanitário o seu valor positivo (SCHWARTZ, 2003).

De qualquer forma, não se pode perder de vista a complexidade que envolve a noção de "saúde" e, por consequência, a ambivalente "doença". A título de exemplificação, no documento internacional que institui a Organização Mundial de Saúde (em 1946), consta a seguinte percepção:

A saúde é um estado de completo bem-estar físico, mental e social, e não consiste apenas na ausência de doença ou de enfermidade. Gozar do melhor estado de saúde que é possível atingir constitui um dos direitos fundamentais de todo o ser humano, sem distinção de raça, de religião, de credo político, de condição econômica ou social. A saúde de todos os povos é essencial para conseguir a paz e a segurança e depende da mais estreita cooperação dos indivíduos e dos Estados. Os resultados conseguidos por cada Estado na promo- 
ção e proteção da saúde são de valor para todos. [...] A extensão a todos os povos dos benefícios dos conhecimentos médicos, psicológicos e afins é essencial para atingir o mais elevado grau de saúde. [...] Os Governos têm responsabilidade pela saúde dos seus povos, a qual só pode ser assumida pelo estabelecimento de medidas sanitárias e sociais adequadas. Aceitando estes princípios com o fim de cooperar entre si e com os outros para promover e proteger a saúde de todos os povos, as partes contratantes concordam com a presente Constituição e estabelecem a Organização Mundial da Saúde como um organismo especializado, nos termos do artigo 57 da Carta das Nações Unidas.

Grande parte dos estudos a respeito de saúde aponta apenas a primeira diretriz como um conceito de saúde. Saúde, então, para além da ausência de moléstias físicas e mentais, seria um estado completo de bem-estar, inclusive social. De qualquer forma, as demais diretrizes indicam outros elementos que auxiliam na interpretação ou na composição daquilo que pode se entender por saúde, inclusive em relação às crianças e à atuação do poder público, na extensão dos benefícios dos conhecimentos médicos a todos e em uma "[...] opinião pública esclarecida [...] para o melhoramento da saúde dos povos" (OMS, 2016).

Essa percepção da saúde, por si só, demonstra a dificuldade de compreensão daquilo que pode se entender como doença na atualidade. Há uma fluidez na semântica de saúde e de doença. E, embora essa não seja propriamente a ênfase de Michel Foucault, o fenômeno de uma construção da situação da anormalidade (como doença) aparece na obra "Os anormais". Exemplo relevante, exatamente porque não encontra tamanha relevância contemporaneamente (indicando contingência na configuração de uma doença, ao menos em relação à intensidade) é o de "[...] quando colocam a questão da masturbação, os médicos da época insistem no fato de que ela não é ligada ao desenvolvimento natural, ao desabrochar natural da puberdade, e a melhor prova disso é que intervém antes" (FOUCAULT, 2010, p. 65). Comparativamente, embora possível o enquadramento na Classificação Internacional de Doenças, atualmente ocorreria em situações excepcionais, porque existe maior aceitação em relação ao século XVIII. 
De qualquer forma, não se constituem novidade as discussões nos meios de comunicação a respeito da configuração ou não de determinados "problemas" observados nas crianças como doenças (hiperatividade, hipoatividade). Igualmente, há inúmeras discussões a respeito da existência ou não de síndromes e doenças decorrentes especificamente do modo de vida contemporâneo, especialmente o ocidental. Por exemplo, “[...] Recentemente, médicos dos EUA criaram uma entidade nosológica e até lhe deram um C.I.D.: é a 'síndrome da felicidade', incompatível com a situação do homem, com suas dificuldades, dúvidas, medos e incertezas" (SEGRE; FERRAZ, 1997, p. 538). Essa doença, "normóticos" ou "normopatas" passou a ser estudada por psicanalistas quando perceberam que "sujeitos, exatamente por não contarem com proteção de uma vida psíquica que lhes dê sustentação para enfrentar os acontecimentos traumáticos da vida, são, segundo tais psicanalistas, os mais propensos à somatização" (SEGRE; FERRAZ, 1997, p. 538).

Além das discussões sobre observações atuais, ainda é possível questionar se dificuldades do cotidiano se configurariam em doenças, em razão de o ser humano sempre ter convivido com alguns tipos de problemas:

Por outro lado, a angústia (com oscilações), tendo essa angústia repercussão somática maior ou menor (por exemplo, um cólon irritativo ou uma gastrite), configura situação habitual, inerente às próprias condições do ser humano. Divergir de posturas da sociedade, e até marginalizar-se ou de ser marginalizado frente a essa mesma sociedade, não obstante o sofrimento que essas situações trazem, é comum e até desejável para o homem sintonizado com o ambiente em que vive. [...] Será que alguém, pelo simples fato de não ter recursos para se alimentar de acordo com nossos padrões, poderá aprioristicamente ser considerado com qualidade pior de vida do que uma pessoa bem alimentada? (SEGRE; FERRAZ, 1997, p. 538)

A discussão levantada nas transcrições - extraídas de um artigo científico, do âmbito das pesquisas em medicina - indica exatamente a dificuldade de compreensão ou de enquadramento de fatos da vida como 
doenças. Tal circunstância não se configura em novidade, como se infere de Foucault. Em outras palavras, há uma variação no conteúdo designativo de doença/saúde. Inobstante a relevância social dessa discussão, esse tipo de percepção é absorvida pelo código da medicina. Isso, porque, após a conclusão a respeito da existência ou não de uma doença - a incorporação do problema no código, em sentido positivo ou negativo -, há a orientação a respeito de como o sistema potencialmente operará. Evidentemente, enquanto há indefinição (sem perder de vista a contingência da possibilidade de modificações futuras), podem ocorrer todos aqueles eventos estudados por Foucault em "Os Anormais", inclusive no que se refere à construção de estruturas jurídicas. Por exemplo, o exame psiquiátrico já viu como "[...] essencial do seu papel é legitimar, na forma do conhecimento científico, a extensão do poder de punir a outra coisa que não a infração" (FOUCAULT, 2010, p. 17), o diferente.

Conforme observa Schwartz (2003), a codificação do sistema possui especificidade em relação às codificações de outros sistemas. Habitualmente, nos outros subsistemas, o código tem um valor positivo e outro negativo. O ponto positivo mostra-se como o enlace da operação interna do sistema. O negativo tem como função a condição de reflexão do sistema (SCHWARTZ, 2003). No entanto, “[ ...] el caso contrario lo constituye el sistema de la salud. Sólo en él, el valor negativo (la enfermedad) posee capacidad de enlace, mientras que la salud sirve sólo de valor de reflexión) [...]"; ou seja, isso é que torna a doença o elemento decisivo na atuação no sistema sanitário (LUHMANN, 2000, p. 61). A doença não pode ser compreendida como antônimo de saúde; ela é um equivalente funcional, em termos sistêmicos. Disso decorre a possibilidade de se afirmar que somente por intermédio do código saúde/enfermidade é que o sistema poderá orientar-se para sua função precípua: a saúde (SCHWARTZ, 2003).

A relevância dessa percepção - e para além de Luhmann - consiste no fato de que os dados referentes ao conjunto de diferenças dos dois aspectos do código integram o sistema. Isso permite o abandono do paradigma patogênico de saúde (cuja ênfase se encontra na doença) e abre-se espaço para um novo: o salutogênico (GUILLOD; SPRUMONT, 1996). 
A ideia de que o sistema sanitário intervém só quando alguém está doente é incorreta, segundo Schwartz (2003), pois se deve pensar no enfrentamento dos riscos sanitários com cautela, com precaução e prevenção e isso incrementa a complexidade do sistema. Em outras palavras, o sistema opera com um código de dois lados, os quais devem ser considerados igualmente importantes. Significa dizer que todos os elementos lógicos que formam a diferença doença-saúde são relevantes, porque estão abarcados pela distinção. Essa não deixa de ser uma exigência da própria fluidez da caracterização saúde-doença, cujos elementos não são distinguíveis de antemão.

O desenvolvimento da medicina e do próprio perfil epidemiológico gera evolução no sistema sanitário (ou médico) e no da saúde. De qualquer forma, tais desenvolvimentos, por via de consequência, também geram como resultado a multiplicação dos riscos e perigos. Novas tecnologias e desenvolvimentos (do âmbito da saúde ou não) multiplicam riscos e perigos. Luhmann apontava que

La razón por la que la problemática del riesgo provoca tantas discusiones en nuestros días, por la que inclusive nuestra sociedad se considera una sociedad de riesgo, tiene que ver fundamentalmente con la velocidad del desarrollo tecnológico en esferas que son científicamente de la competencia de la física, la química y la biología. (LUHMANN, 2007 p. 131)

Tais âmbitos científicos estão inexoravelmente ligados - direta ou indiretamente - com o código da medicina, com a saúde e com a doença, especialmente no que se refere a diagnóstico, tratamento e cura. As mudanças estruturais a partir de seu próprio código dão ao sistema uma característica evolutiva a que ele não pode deixar de se apegar, porque a experiência prática indica que quanto mais se sabe, pesquisa e conhece, "[...] más se constituye una consciencia del riesgo" (LUHMANN, 2007, p. 74). Logo, a estruturação do código sanitário corrobora e reafirma a noção de que a saúde deve ser pensada a partir da própria saúde, tendo em vista que a doença é a mola que propulsiona os elementos que (r)estabilizarão o sistema. Ambos os polos pretendem a busca pela saúde, nunca a doença (SCHWARTZ, 2003). 
Para Luhmann (2007), a doença é a realidade, e a saúde é a reflexão e função, de forma que a realidade é necessária para o sistema sofrer as irritações oriundas do ambiente. Essa ideia, todavia, contemporaneamente, explica de maneira insuficiente o papel da prevenção.

É oportuno destacar que ainda não há definição e consenso acerca de qual seria o código binário do sistema da saúde. Isso dificulta a observação da prevenção no que tange ao seu "espaço". Todavia, observando as questões estruturais do sistema da saúde, nota-se que a instrumentalização da prevenção ocorrerá no sistema médico (por exemplo, a partir de um diagnóstico preventivo e/ou reabilitação), bem como no sistema da saúde. Este, por sua vez, considerará as comunicações sanitárias (por exemplo, o perfil epidemiológico de determinada região ou população) e, por meio de suas estruturas internas (por exemplo, a vigilância sanitária), estabelecerá ações de caráter preventivo. Diante de tais ressonâncias comunicacionais, está, por sua vez, o direito, sendo instado - pela dogmática jurídica e pelo sistema social - a garantir formas de efetividade a um direito subjetivo cuja "semântica" se altera a partir da tradução pelo sistema jurídico da comunicação sanitária.

\section{Novos Horizontes para o Sistema Médico e o Sistema da Saúde no Contexto da Prevenção}

Segundo Martini (2015), qualquer direito universal, qualquer valor, na perspectiva luhmanniana, pode ser constitucionalizado. Foi isso que aconteceu com a saúde, especialmente no âmbito brasileiro, na Constituição Federal de 1988.

Havendo o reconhecimento desse direito, é função dos sistemas sociais legitimá-lo e efetivá-lo - sem perder de vista os "[...] elementos políticos-ideológicos desde sus orígenes históricos, sufriendo influencias de las mutaciones de las formaciones sociales [...]" (ROCHA, 2016, p. 13). Em um sistema da saúde, a organização é operada com as políticas públicas, a partir de decisões coletivamente vinculantes do sistema da política. Tais decisões determinam a organização das unidades básicas de saúde, dos hospitais, dos ambulatórios e também das técnicas utilizadas 
(MARTINI, 2015), sem falar dos grupos de trabalhadores e das pessoas envolvidas com a promoção e o restabelecimento da saúde (incluindo-se, também médicos). Martini (2015) chama a atenção para o estreito âmbito de atuação do sistema, que também é uma forma de possibilidade da reflexão acerca do sistema médico, tendo em vista que esse sistema não opera com o conceito ampliado de saúde. Aqui, como regra, a saúde é vislumbrada como mera ausência de doença.

De qualquer forma, como visto, conforme a definição instituída no documento de criação da Organização Mundial da Saúde (OMS), é necessário, no mínimo, ampliar o conceito. É desnecessário lembrar que Luhmann, quando estudou o sistema médico, não tinha a preocupação com a dimensão moderna do conceito de saúde, do "direito ao direito à saúde", nem mesmo a realidade jurídico-dogmática existente no Brasil. A ênfase de sua observação estava na compreensão de um sistema a partir da lógica médica. Em outras palavras, analisava a peculiaridade de o sistema médico operar a partir do código negativo, com a doença (e não propriamente com o código positivo). Essa concepção, por si só, quando se analisa a sociedade atual, demanda uma nova discussão sobre o tema e a necessidade de se discutir e observar o sistema da saúde (MARTINI, 2015). Em outras palavras, o sistema médico concebido na lógica de operação baseada na doença não é suficiente para abarcar a complexidade atual. É preciso alarga-se o conceito de saúde e transcender, na teoria dos sistemas, o conceito de saúde como mera ausência de doença; é preciso vislumbrar-se espaço para a prevenção ${ }^{10}$.

Considerando esses pressupostos sistêmicos, a sociedade é um grande sistema social composto por subsistemas. É constituída por comunicação, elemento básico da sociedade, por uma malha, uma rede de comunicação, o que rompe com as delimitações territoriais/políticas $(\mathrm{ROCHA}, 2017)^{11}$. Da mesma forma, as doenças também rompem com

\footnotetext{
${ }^{10}$ Note-se, por exemplo, as teorias ligadas à administração possuem concepções sistêmicas com um quadro conceitual diferenciado, mas que podem auxiliar na inserção da prevenção no sistema da saúde. Talvez fosse possível pensar o sistema da saúde brasileiro como uma "organização que apreende", que necessita tomar decisões em um ambiente complexo e contingencial, de modo que deve ser aplicada uma alavancagem específica. Sobre o tema, ver, por exemplo, Senge (2014).

${ }^{11}$ Ver, também, Moeller (2006, p. 24).
} 
essas barreiras, e o sistema da saúde ou o médico precisam dar respostas, inclusive por meio da prevenção. Tanto no sistema da medicina quanto no sistema médico, nenhum dos seus códigos faz alusão à prevenção (o sistema médico envolve a promoção da saúde, que é totalmente distinta da prevenção).

Deve-se pontuar que são características dessa sociedade a complexidade, a contingência, a paradoxalidade e o risco, dentre outras ${ }^{12}$. Pode-se dizer que um sistema é complexo na medida em que apresenta mais possibilidades do que pode realizar em dado momento. Há a necessidade de o sistema fazer uma seleção dessas possibilidades, sob pena de não mais continuar operando, e o sistema da medicina seleciona a doença e opera a partir dela, nunca (ou quase nunca) a partir da prevenção. Ou seja, o sistema da medicina reproduz o modelo biomédico (paradigma muito criticado no ocidente, em especial por visualizar tão somente a dualidade doença-cura; na contemporaneiadade, os sistemas nacionais de saúde demandam respostas que ultrapassam o modelo curativo e o bioméidico).

E é nesse contexto de interação sistêmica (complexa) que as expectativas normativas em relação à saúde passaram, a partir de 1988, a serem garantidas em diversas normas constitucionais podendo-se aqui destacar, especialmente, os seus artigos 6º 194, 196 e seguintes. A inserção da saúde em nível constitucional entre os direitos sociais que compõem os Direitos e Garantias Fundamentais da República Federativa do Brasil (Título II, Capítulo II, art. $6^{\circ}$ ), bem como no "conjunto integrado de ações de iniciativa dos Poderes Públicos e da sociedade", que compõe a Seguridade Social (Título VIII, Capítulo II, art. 194), é de suma importância para a discussão da saúde (em relação a sua comunicação interna e com as ressonâncias comunicacionais que impactam nos outros sistemas, no caso, com destaque, o direito. No que diz respeito ao artigo 196 da Constituição Federal de 1988, cumpre fazer ainda um destaque, no sentido de que, em seu texto, há previsão de que

A saúde é direito de todos e dever do Estado, garantido mediante políticas sociais e econômicas que visem à redução do risco de

${ }^{12}$ Sobre o tema, entre outros, ver: Luhmann (1990, p. 69) e Rocha, Schwartz e Clam (2013). 
doença e de outros agravos e ao acesso universal e igualitário às ações e serviços para sua promoção, proteção e recuperação. (BRASIL, 1988, art. 196)

$\mathrm{E}$, aqui, não há dúvida a respeito dos acoplamentos que estão relacionados entre os sistemas, notadamente em relação à conexão efetividade-prevenção.

Assim, o sistema sanitário e os demais sistemas sociais que compõem a sociedade brasileira redefinem sua responsabilidade e a do próprio Estado na organização do sistema sanitário nacional. A sociedade compromete-se a viabilizar políticas públicas sociais e econômicas com o objetivo de reduzir "os riscos de doença e de outros agravos" numa dimensão preventiva, que não pode mais ser satisfeita simplesmente pela manutenção de um sistema assistencial médico-curativo (sistema biomédico), privatista e discriminador, como aquele desenvolvido até 1988.

Nesse sentido, “[...] o acesso universal e igualitário às ações e serviços para a sua promoção, proteção e recuperação [...]" deve garantir a todos o direito de não apenas serem atendidos pelos serviços assistenciais curativos do Sistema Único de Saúde (SUS), como também de serem alcançados pelas ações e demais políticas públicas voltadas à prevenção e à promoção de sua saúde de maneira geral. A promoção da saúde deve ser entendida não apenas como a cura e a prevenção de doenças, mas de forma mais abrangente e interdisciplinar relacionada à garantia da qualidade de vida enquanto questão intrinsecamente ligada à saúde. Apresenta-se, portanto, como "[...] um processo que se constrói e que se modifica, sofrendo influência de todos os demais sistemas sociais" (SCHWARTZ, 2004, p. 102). Em outros termos, as operações sistêmicas relacionadas à saúde, independentemente de sua origem e extensão, devem partir de uma conformação mínima às normas constitucionais, como expectativas normativas garantidas pela Constituição e, assim, compartilhadas por todos os sistemas sociais.

É inegável a persistência de um subsistema assistencial médico-curativo de responsabilidade pública (conforme afere o texto constitucional de 1988), com a sua devida adequação aos novos valores sociais e à rele- 
vância pública e ampliação de sua rede de proteção no sentido de acesso universal e da integralidade de seus serviços buscando a superação do anterior sistema essencialmente biomédico, autoritário e privatista.

Dada a conformação do sistema sanitário brasileiro e a persistente influência do modelo biomédico na organização da saúde brasileira, faz-se necessário repensar o papel da prevenção nas políticas públicas de saúde, visto que o modelo biomédico não abre espaço para a prevenção (que é diferente de promoção).

Como já dito anteriormente, a teoria sistêmica da sociedade diferenciada funcionalmente não tratou do sistema da saúde, mas sim apenas do sistema médico, que possui um código binário expresso em são/doente; programa representado pelo juramento de Hipócrates, no qual o medium é representado pelos tratamentos e procedimentos de cura, ou seja, como função a assistência e os cuidados da doença. Para Luhmann, o valor que interessa à medicina é o positivo, expresso na doença, pois é esta que interessa aos médicos (LUHMANN, 2015). Contudo, saúde significa muito mais que medicina, e tal como positivado na Constituição de 1988, mais que um direito. Saúde é, normativamente, um subsistema do sistema da seguridade social, formado também pelos subsistemas da previdência social e da assistência social. Essa estruturação implica concorrência de saberes outros que não exclusivamente o médico, constituindo-se mesmo em uma área hipercomplexa de conhecimentos aplicáveis em caráter preventivo e repressivo das doenças. E, ao mesmo tempo, acarretam necessidades de tradução para o direito a cada vez que é demandado a atuar na socidade, sobretudo por conta de seu fechamento operacional, que faz a distinção sistema-direito com o ambiente (como todos os demais sistemas).

Embora haja uma diferenciação entre sistema e ambiente, este exerce irritações naquele, e o sistema tende a ficar mais complexo. Por exemplo, quando surgem novas doenças ou epidemias, tais como, por exemplo, a epidemia do vírus zika, há uma irritação no sistema médico. Imagine-se a situação de um paciente ser levado a um centro de atendimento e não haver capacidade de diagnóstico e/ou tratamento da doença. O médico ainda que possa tratar sintomas -, na perspectiva da cura, opera na escuridão. A irritação é o que enseja o sistema a "auto-produzir-se", ou seja, 
essa irritação provocada pelo ambiente estimula a autopoiese do sistema. Conforme aponta Luhmann (1997, p. 68), “[...] as irritações se dão sempre inicialmente a partir de diferenciações e comparações com estruturas internas aos sistemas, sendo, portanto, do mesmo modo que a informação, produto do próprio sistema". Ainda que nem tudo gere irritação no sistema (imagine-se um paciente que faleça por causa desconhecida), em algumas possibilidades, o ambiente irritará o sistema. O Zika Vírus, por exemplo, pode ensejar modificações no sistema da medicina, no que tange ao tratamento e diagnóstico, bem como no sistema da saúde, nas estruturas internas de vigilância sanitária que deverão abarcar as irritações do vírus no contexto da epidemia a fim de "evitar" (prevenir) que a doença se alastre.

Apenas a título de exemplo da importância da prevenção no caso brasileiro, a respeito zika vírus, o Boletim Epidemiológico do Ministério da Saúde (2017), indica que, por conta das ações de prevenção no ano de 2016 (que totalizam vinte e oito medidas, desde financiamento, entrega de kits para combate ao mosquito e Workshops), “em 2017, até a SE 12 [Semana Epidemiológica 12], não foi confirmado laboratorialmente nenhum óbito por Zika Vírus":

Figura 1 - Óbitos em investigação e confirmados por febre de chikungunya, por mês de ocorrência do óbito, Brasil, 2017

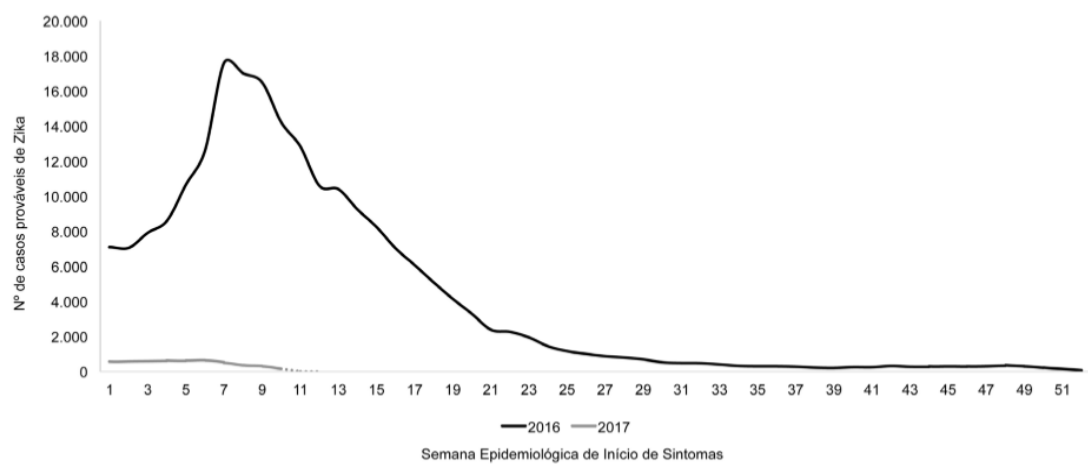

Fonte: Brasil (2017) 
Em outras palavras, prevenir está de algum modo inserido entre a saúde e a doença. Não existindo a potencialidade da doença, não há sentido falar-se em prevenção. Da mesma forma, havendo uma situação de saúde (especialmente considerando o conceito amplo da Organização Mundial da Saúde), não há o que prevenir. E, no mesmo sentido, também acaba sendo trazido pelo direito, como a permissão para o aborto em casos de microcefalia e, mais recente, a possibilidade de indenização.

Essa "irritação" de uma nova doença do ambiente para com o sistema da medicina e o da saúde - e para com o sistema do direito - pode ser entendida como um "estímulo" do ambiente. Deve-se dizer que é o sistema que se irrita com o ambiente, é o sistema que seleciona as possibilidades que estão no seu entorno: um mesmo elemento pode ser selecionado por diferentes sistemas. Sobre a irritação, Luhmann (1997, p. 42) indica que

O ambiente não contribui para nenhuma operação do sistema, mas pode irritar ou perturbar (como diz Maturana) as operações do sistema somente quando os efeitos do ambiente aparecem no sistema como informação e podem ser processados nele como tal.

Assim, o sistema tem de se adaptar à duplicidade de complexidade: a do ambiente e a dele próprio. Caso o sistema não tivesse essa preocupação em diminuir a complexidade, ele estaria imerso no caos, deixaria de ser um sistema. Eis o espaço para a prevenção no sistema da saúde: a existência de uma doença capaz de gerar irritação (nem o fazem) enseja a inclusão na semântica do ambivalente funcional "saúde" a noção de prevenção. Assim, as medidas preventivas acabam sendo processadas a partir das estruturas sanitárias.

A partir do próprio referencial teórico, as hipóteses nas quais dogmaticamente se reconhece a necessidade de medidas preventivas podem ser pensadas como "programas". Para Luhmann, programas consistem em "[...] algunas condiciones ulteriores que establezcan en qué circunstancias la atribución del valor positivo y en qué circunstancias la atribución del valor negativo son correctas o falsas" (LUHMANN, 2007, p. 294). Nesse sentido, "[...] todos los valores que se excluyen, en este nivel, debido a la binaridad del código pueden reintroducirse como puntos de vista de la elección del programa" (LUHMANN, 2007, p. 295). 
A prevenção poderia exercer, da mesma forma que as leis, decisões judiciais e contratos podem ser programas ligados ao código do Direito, estabelecendo as condições nos quais é aplicado (LUHMANN, 2007); direito/não direito (ou outras nomenclaturas), um papel de condicionador da aplicação do código saúde/doença. Em outras palavras, havendo a irritação do sistema a partir da comunicação e reconhecidas determinadas circunstâncias, o programa (prevenção) determina a aplicação do código saúde/doença, de forma unitária. E isso significa, por outro lado, a possibilidade de reconhecimento dogmático pela existência de um efetivo direito à prevenção (dentro de diversas possibilidades de aplicação) por conta da necessidade de efetividade do direito à saúde.

Assim, as comunicações sanitárias participam dessas irritações, o sistema da medicina e o da saúde percebem as informações, processam-nas em consonância com o seu código binário próprio; todavia, com o programa condicionador: não há input de informações, pois o sistema é irritado, e dessa irritação o próprio sistema fará a seleção do que é relevante para ele - de acordo com a função por ele desenvolvida (saúde) - e, dadas as condições previstas no programa, enseja a aplicação do código, ainda que não exista propriamente a doença. De fato, o programa permite antecipar o estado "doença", direcionando a atuação do sistema (como se existisse uma efetiva doença): uma potencialidade transformada pelo observador em realidade.

Deve-se, por outro lado, observar que a semântica de "saúde" (cujo conceito é fluído, como visto), operacionalizada a partir do código binário próprio, pode ser o mecanismo que proporciona a "abertura cognitiva" do sistema à prevenção. Luhmann, ao trabalhar o sistema médico, escreveu aproximadamente quatorze páginas acerca do tema, sem chegar a discutir a prevenção. Entretanto, isso não significa que não seja possível realizar essa análise a partir do sistema médico (e da saúde). O próprio código binário do sistema é uma chave para o espaço de construção da prevenção a partir de um processo de atribuição de sentido ao próprio código. Luhmann reconhece que a semântica dos elementos do código podem ser variações, as quais, de qualquer forma, são controladas pelo próprio sistema. E, “[...] las 'reservas' semánticas tanto del derecho como de la ciencia consisten, por ejemplo, de programas" (LUHMANN, 2007, p. 
282). Em outras palavras, “[...] en el transcurso evolutivo de los códigos se forma una semántica de criterios adicionales para determinar en qué condiciones la clasificación del valor positivo o negativo se lleva a cabo correctamente". Segundo o autor,

[...] se adhieren a los códigos respectivos en calidad de enormes aparatos semánticos, y mientras los códigos logran sencillez e invariabilidad, el ámbito de sus programas se carga - casi como suplemento - de complejidad e variabilidad. (LUHMANN, 2007, p. 282)

Para Baraldi, a crise da medicina ocidental se refere à interação entre médico e paciente, calcada não mais na comunicação entre eles, mas sim sobre um complexo sistema tecnológico de aferição do diagnóstico. A isso acresça-se o relevante fato de o sistema médico ter de tratar de uma clientela multiétnica, o que gera problema de tipo linguístico - acentuação da improbabilidade da compreensão - e de tipo cultural - acentuação da improbabilidade da aceitação (BARALDI, 2015). É esse o desafio da prevenção no contexto das políticas públicas: provocar interação e respostas nesse "ambiente" altamente complexo e não efetivo do modelo biomédico, no qual médico e paciente não comunicam e que, ao mesmo tempo, o direito é demandado a solucionar problemas a partir de suas possibilidades.

O código binário da política pública, sob a ótica da teoria dos sistemas, é o binômio inclusão/exclusão. É adequado afirmar que a busca de prevalência da inclusão, em especial quanto à efetivação do direito fundamental à saúde, demanda a análise semiótica do sistema no sentido de se reconhecer fatores externos a este, em especial a evolução científica.

Em tal contexto, a definição de ações preventivas ou as políticas públicas estão alicerçadas nas intervenções orientadas a evitar o surgimento de doenças específicas, reduzindo, assim, sua incidência e prevalência nas populações e grupos. A base para essas intervenções são os conhecimentos epidemiológicos das doenças e de outros agravos específicos (agentes de risco) (CZERESNIA; FREITAS, 2003, p. 15-38), conforme o desenvolvimento técnico-científico do momento. 
Além disso, considerando que a prevenção orienta todas as ações de detecção, de controle e de enfraquecimento (e diminuição) dos fatores de risco de enfermidades, o cerne é a doença e como atacá-la (BUSS, 2003), de forma que esse controle se dá de forma interna ao sistema da saúde, mais amplo e, ao mesmo tempo, acoplado ao sistema médico.

Ocorre que o paradigma do modelo assistencial abarca a organização das ações para intervenção no processo saúde/doença, articulando, assim, os recursos físicos, tecnológicos e humanos para enfrentar/elidir os problemas de saúde existentes na sociedade (PAIM, 1994). Para isso, a prevenção faz uso de medidas gerais, educativas, que têm como objetivo aumentar a resistência e o bem-estar dos indivíduos, incluindo, ainda, comportamentos alimentares, exercício físico e repouso, contenção de estresse, não ingestão de drogas ou de tabaco, dentre outros comportamentos, com o fito de que os indivíduos resistam às agressões dos agentes causadores de patologias, crônicas ou não, transmissíveis ou não. Essa atuação - de maneira integral -, dentre outras de possível inclusão e implementação, conforme as semânticas do código e do programa, estão no âmbito do sistema da saúde, que abarca mais que o sistema médico. Talvez, o sistema médico devesse ser incluído como subsistema do sistema da saúde, fazendo uso de um código saúde/doença mais restrito (doenças já reconhecidas, por exemplo) em relação ao sistema da saúde, cujo código possui uma semântica mais fluida. Dentro dessa lógica, é possível vislumbrar a atuação do médico em relação ao diagnóstico de doenças de comunicação compulsória aos órgãos governamentais. Havendo o diagnóstico pelo valor negativo (doença reconhecida), o sistema médico concretiza sua atuação, assim como comunica (provocando irritações ou não) no sistema da saúde. Da mesma forma, ingressando um paciente com sintomas e doença não conhecida pelo sistema médico, esse realiza as atuações dentro de suas possibilidades (porque reconhece a existência do equivalente negativo, doença) e gera comunicações que podem irritar os demais sistemas, como da saúde, da ciência, da política, etc. 


\section{Conclusão}

O presente trabalho buscou observar a relação da prevenção com o código do sistema da medicina e a construção da relação entre este sistema e o sistema da saúde (assim como seu código). Visando a esse objetivo propositivo, partiu-se dos escritos preliminares de Luhmann a respeito do sistema médico, conjugando-os com os estudos de pensadores contemporâneos como Martini e Schwartz, os quais também discutem a saúde na teoria dos sistemas sociais.

Assim, reconstruiu-se a perspectiva inicial de Luhmann a respeito do sistema médico, explicitando seus elementos de configuração e, conjuntamente, o diferenciam de outros sistemas. Em um segundo ponto, observou-se a peculiaridade do código do sistema da medicina, discutindo-o a partir de aportes daquilo que pode ser entendido como sistema da saúde. Por fim, procurou-se compreender a inserção do papel da prevenção - elemento de relevância no que se refere à saúde pública contemporânea -, sobretudo enfatizando a semântica fluida do conceito de saúde/doença, de forma a incorporá-la no código do sistema médico.

Inclusive, no âmbito de um contexto de prevenção, percebeu-se uma maior amplitude daquilo que pode se entender como sistema da saúde, em relação ao sistema médico, este restrito à relação médico-doente. De qualquer forma, em razão da mesma flexibilização semântica dos ambivalentes funcionais do sistema médico, observou-se a possibilidade de aplicação do mesmo código ao sistema da saúde. Além disso, buscou-se discutir a importância e a complexidade do papel do direito em relação à efetividade do direito à saúde, na medida em que, reconhecendo-se uma "ampliação" da semântica histórica do direito à saúde, há novas possibilidades de atuação dogmática no direito em busca da efetividade.

E, nesse contexto, de forma propositiva e preliminar, sugeriu-se a observação do sistema da medicina como subsistema do sistema da saúde, ambos integrados pelo mesmo código, saúde/doença, o qual contempla, necessariamente, a prevenção. Esta se insere sistemicamente, quer pela forma de programas condicionais, quer pela própria semântica fluida da ambivalência saúde/doença, variável no tempo e espaço. 
Nesse sentido, sugeriu-se que ambos os sistemas se acoplam, permitindo irritações recíprocas, e operam a partir de seus próprios elementos específicos, de maneira autopoiética. E, ao mesmo tempo, acarreta ressonâncias no sistema do direito, que acaba buscando soluções a paritr de seu próprio código, também fazendo uso da ideia de efetividade de um direito que, por sua vez, depende da prevenção.

Evidentemente, em razão da natureza do trabalho, não há dúvida de que são necessários novos debates e aprofundamentos, o que este texto inicial pretende provocar na comunidade científica.

\section{Referências}

BARALDI, Claudio. Teoria dei sistemi social e forme dell'interazione medico-paziente. In: CORSI, Giancarlo Ca cura de. Salute e malattia nella teoria dei sistemi: a partire da Niklas Luhmann. Milano: FrancoAngeli, 2015. p. 13-27.

BRASIL. Boletim Epidemiológico - Monitoramento dos casos de dengue, febre de chikungunya e febre pelo vírus Zika até a Semana Epidemiológica 12, 2017. Brasília: Ministério da Saúde, 2017. Disponível em: http://portalarquivos.saude.gov.br/images/pdf/2017/ abril/06/2017-010-Monitoramento-dos-cas os-de-dengue--febre-dechikungunya-e-febre-pelo-virus-Zika-ate-a-Semana-Epidemiol--gica-12 --2017.pdf. Acesso em: 22 abr. 2017.

BUSS, P. M. Uma introdução ao conceito de Promoção da Saúde. In: CZERESNIA, D.; FREITAS, C. M. (org.) Promoção da saúde: conceitos, reflexões, tendências. Rio de Janeiro: Editora Fiocruz, 2003. p. $15-38$.

CORSI, Giancarlo; BARALDI, Cladio; ESPOSITO, Elena. Luhmann in Glossario: i concetti fondamentali dela teoria dei sistemi social. Milano: Franco Angeli, 1996.

CZERESNIA, D.; FREITAS, C. M. (org.) Promoção da saúde: conceitos, reflexões, tendências. Rio de Janeiro: Editora Fiocruz, 2003. 
FOUCAULT, Michel. Os Anormais. São Paulo: Martins Fontes, 2010. GUILLOD, Olivier; SPRUMONT, Dominique. Le Droit à Ia Santé: un droit en emergence. In: ZEN-RUFFINEN, Piermarco; AVER, Andreas (ed.). De la Constitution: etudes en I'honneurde Jean-François Aubert. Berne: Helbing \& Lichtenhahn, 1996. p. 32-45.

HERZLICH, Claudine. Saúde e doença no início do século XXI: entre a experiência privada e a esfera pública. Physis, Rio de Janeiro, v. 14, n. 2, p. 383-394, jul. 2004. Disponível em: http://www.scielo. br/scielo.php?script=sci_arttext\&pid=S0103-7331200400020 0011\&lng=pt\&nrm=iso. Acesso em: 22 abr. 2017.

LUHMANN, Niklas. Der Medizinische Code. In: Soziologische Aufklärung 5: Konstruktivistische Perspektiven, Westdeutscher Verlag, Opladen: 1990; Tradução em italiano: LUHMANN, Niklas. Il codice della medicina. Salute e malattia nella teoria dei sistemi. Milano: FrancoAngeli, 2015. p. 183-195.

LUHMANN, Niklas. O conceito de sociedade. In: NEVES, C. B.; SAMIOS, E. M. B. (org.). Niklas Luhmann: a nova teoria dos sistemas. Porto Alegre: UFRGS, 1997. p. 56-62.

SCHWARTZ, Germano. A autopoiese do sistema sanitário. Revista de Direito Sanitário, [S.l.], v. 4, n. 1, março de 2003.

LUHMANN. Niklas. La Realidad de los Medios de Masas. Barcelona: Anthropos Editorial; México: Universidad Iberoamericana, 2000.

LUHMANN, Niklas. La Sociedad de la sociedad. México: Editorial Herder, colaboração Universidad Iberoamericana, 2007.

LUHMANN, Niklas. Sociedad y Sistema: la ambición de la teoria. Barcelona: Paidós, 1990.

LUHMANN, N.; DE GIORGI, Raffaele. Teoria della società. Milão: Franco Angeli, 1996.

MANSILLA, Darío Rodríguez. La Teoría de la Sociedad: invitación a la sociología de Niklas Luhmann. Metapolítica, México, DF, v. 5, n. 20, 2001. 
MARTINI, Sandra Regina. Sistema social da saúde e a Teoria Sistêmica de Luhmann. Revista de Direito Sanitário, São Paulo, v. 16, n. 1, p. 112-127, mar.-jun., 2015.

MATURANA, Humberto; VARELA, Francisco. De Máquinas e Seres Vivos: autopoiese - a organização do vivo. Porto Alegre: Artes Médicas, 1997.

MOELLER, Hans-Georg. Luhmann Explained: from souls to systems. Chicago: Open Court Books, 2006.

OMS - ORGANIZAÇÃO MUNDIAL DA SAÚDE. Estresse no ambiente de trabalho cobra preço alto de indivíduos, empregadores e sociedade. 4 de maio 2016. Disponível em: http://www.paho.org/bra/ index.php?option $=$ com_content $\&$ view $=$ article $\& i d=5087$ :estresse-noambiente-de-trabalho-cobra-preco-alto-de-individuos-empregadores-e-so ciedade\&catid=845: noticias \&Itemid $=839$. Acesso em: 22 abr. 2017.

PAIM, J. S. A Reforma Sanitária e os Modelos Assistenciais. In: ROUQUAYROL, M. Z. Epidemiologia \& Saúde. Rio de Janeiro: MEDSI, 1994. p. 455-466.

RAMDOM, Michel. O Território do Olhar. In: RAMDOM, Michel. Educação e Transdisciplinaridade II. Coordenação executiva do CETRANS. São Paulo: TRIOM, 2002. p. 98-113.

ROCHA, Leonel Severo. A produção sistêmica do sentido do direito: da semiótica à autopoiese. In: MORAES, Jose L. B.; STRECK, Lenio L. (org.). Constituição, Sistemas Sociais e Hermenêutica. Porto Alegre: Livraria do Advogado; São Leopoldo: UNISINOS, 2010. p. 165-186. ROCHA, Leonel Severo. Direito e Autopoiese. In: ENGELMANN, Wilson; ROCHA, Leonel Severo; STRECK, Lenio Luiz (org.).

Constituição, Sistemas Sociais e Hermenêutica. Porto Alegre: Livraria do Advogado; São Leopoldo: UNISINOS, 2017. p. 123-136.

ROCHA, Leonel Severo. La Problemática del Discurso Jurídico:

(des)legitimando el poder soberano del estado contemporâneo. Curitiba: Editora Prismas, 2016. 
ROCHA, Leonel Severo; SCHWARTZ. Germano; CLAM, Jean.

Introdução à teoria do sistema autopoiético do direito. Porto Alegre: Livraria do Advogado, 2013.

ROMESÍN, Roberto Maturana; GARCÍA, Francisco Varela. De máquinas e seres vivos - autopoiese: a organização do vivo. Tradução de Juan Acuña Llorens. Porto Alegre: Artes Médicas, 1997.

SCHWARTZ, Germano. A autopoiese do sistema sanitário. Revista de Direito Sanitário, [S.l.],v. 4, n. 1, março de 2003.

SENGE, Peter M. A Quinta Disciplina: a arte e a prática da organização que aprende. Rio de Janeiro: Best Seller, 2014.

SEGRE, Marco; FERRAZ, Flávio Carvalho. O conceito de saúde. Revista de Saúde Pública, São Paulo, v. 31, n. 5, p. 538-542, oct., 1997. VASCONCELLOS, Maria José Esteves de. Pensamento Sistêmico: o novo paradigma da ciência. Campinas: Papirus, 2013.

\section{Leonel Severo Rocha}

E-mail: leonel.rocha@icloud.com

https://orcid.org/0000-0002-6971-1412

Pós-doutor em Sociologia do Direito pela Universita degli Studi di Lecce - Itália e Doutor pela Ecole des Hautes Etudes en Sciences Sociales de Paris. Atualmente é Professor Titular da Universidade do Vale do Rio dos Sinos, e Professor do PPGD da Universidade Regional Integrada do Alto Uruguai (URI), onde Coordena a Catedra Warat; Professor Visitante da Faculté de Droit da Universidade de Paris 1. Bolsista Produtividade do CNPq. Tem experiência na área de Direito, com ênfase em Teoria Geral do Direito, trabalhando principalmente os seguintes temas: Teoria dos Sistemas Sociais, Constitucionalismo, Democracia e Teoria do Direito. 
Endereço profissional: Av. Unisinos, n. 950, Cristo Rei, São Leopoldo, RS. CEP: 93022-750.

\section{Gabrielle Jacobi Kòlling}

E-mail:koll.gabrielle@gmail.com

https://orcid.org/0000-0003-2225-555X

Doutora em Direito Público (UNISINOS). Pesquisadora do Direito nas áreas: Teoria dos Sistemas Sociais; Direito Sanitário, Regulatório, Governança e Políticas Públicas de Saúde e Educação. Professora concursada na Universidade Municipal de São Caetano - USCS. Professora da Universidade São Francisco/ Bragança Paulista, SP. Líder do Grupo de Pesquisa do CNPq "Tutela jurídica da saúde ambiental".

Endereço profissional: Av. Goiás, n. 3.400, Barcelona, São Caetano do Sul, SP. CEP: 09550-051.

\section{Gustavo Andre Olsson}

E-mail: gustavo.olsson@yahoo.com.br

Doutor em Direito Público (UNISINOS) e Professor da Graduação em Direito na UNISINOS/RS. Pesquisas nas áreas de Ciências Criminais, Sociologia Jurídica, Antropologia Jurídica, Filosofia Jurídica, Economia Comportamental, Direito Penal, Processual Penal, Análise Econômica e Teoria Sistêmica.

Endereço profissional: Av. Unisinos, n. 950, Cristo Rei, São Leopoldo, RS. CEP: 93022-750. 